\title{
A Gender-Based Study of Sensation Seeking in Patients with Coronary Artery Disease Compared with Healthy Subjects
}

\author{
Davoud Ezzati ${ }^{1}$, Touraj Hashemi Nosrat Abad ${ }^{1}$, Jalil Babapour \\ Kheiroddin ${ }^{1}$, Hossein Namdar ${ }^{2, *}$, Mohammadreza Taban \\ Sadeghi ${ }^{2}$, Masoumeh Hakimi ${ }^{3}$, Babak Sadeghi ${ }^{1}$, Zhila Samani ${ }^{2}$ \\ ${ }^{1}$ Department of Psychology, School of Psychology, University of Tabriz, Tabriz, \\ Iran \\ ${ }^{2}$ Cardiovascular Research Center, Tabriz University of Medical Sciences, Tabriz, \\ Iran \\ ${ }^{3}$ Department of Psychology, School of Psychology, Azad University, Branch of \\ Tabriz, Iran \\ * Corresponding author: Hossein Namdar, Cardiovascular Research Center, Tabriz \\ University of Medical Sciences, Tabriz, Iran.E-mail: namdar.hn@gmail.com
}

DOI: $10.21859 / \mathrm{ijcp}-03102$

Submited: 09-18-2017

Accepted: 12-12-2017

\section{Keywords:}

Coronary Artery Disease

Sensation Seeking

Sex

(C) 2018. International Journal of Cardiovascular Practice.

\begin{abstract}
Introduction: The relationship between psychological factors and Coronary Artery Disease $(\mathrm{CAD})$ is one of the topics that has occupied the minds of researchers in the field of health psychology. The present research aimed at studying the levels of sensation seeking in coronary patients and healthy subjects.

Methods: Two hundred and twenty-three coronary patients and 255 healthy subjects completed the Sensation Seeking Scale-form V (SSS-V). Next, 100 coronary cases (50 males and 50 females) that had referred to Madani Heart Hospital, Tabriz, Iran, and 100 healthy subjects, were compared in terms of levels of sensation-seeking. All participants were selected by purposeful sampling (aged 25 to 64 years). Data were analyzed by Multivariate Analysis of Variance (MANOVA) through the SPSS 18 software.

Results: Coronary male patients scored higher than coronary female patients in thrill and adventure seeking and healthy males scored higher than healthy females in boredom susceptibility. Healthy females scored higher than coronary females in thrill and adventure seeking, and in boredom susceptibility subscale, healthy males scored higher than coronary males.

Conclusions: The identification of individuals with sensation seeking features will allow the identification of susceptible coronary patients for preventive procedures.
\end{abstract}

\section{INTRODUCTION}

Cardiovascular diseases are among the most common diseases, which annually result many human deaths in most countries. In etiological terms, most cardiovascular diseases fit within the cluster of psychosomatic disorders. Thus, psychological factors are also emphasized in their formation [1]. Coronary Artery Disease (CAD), the most prevalent cardiovascular disease, is a multi-factorial state, resulting from the convergence of genetics, environmental states, and lifestyle. Traditional risk factors of CAD include family history, hypertension, smoking, dyslipidemia, diabetes mellitus, physical inactivity, and obesity [2]; it has been evaluated that nearly $50 \%$ of new CADs cannot be explained on the basis of standard risk factors indicating that a more diverse range of risk factors play a role in the context of $\mathrm{CAD}$ [3]. Besides these standard risk factors, extensive evidence from the literature indicates that psychological and psychosocial variables could have a significant impact on incidence and progression of
CAD [4]. Socioeconomic status, psychological distress, hostility, personality, depression, and social support are among the psychosocial variables that were associated with the pathogenesis and expression of CAD [4-6]. Among the psychological variables, personality features have been indicated to have greater explanatory power than other psychological factors [4-6]. Many studies have addressed the effects of psychological variables on physiological indicators [7-10], and showed that different personality traits affect cardiovascular reactions, since experience and regulation of emotions are linked with cardiovascular responses [11]. Sensation seeking is a biologically-based mood and personality variable, and reflects personal differences in levels of arousal. Sensation seekers prefer constant brain stimulation, tire of monotony, and constantly seek to arouse themselves through exciting experiences. On the contrary, low sensation seekers prefer lower levels of brain stimulation, and tolerate monotonous 
tasks relatively well [12]. Sensation seeking has four secondary parts. Thrill and adventure seeking is the tendency for physical danger and solo non-competitive activities, which requires personal risk and struggle, such as parachuting, diving, and fast driving. Experience seeking is inclination to pursue experience through mind and senses. Painting, music and some opiates indicate pursuing experience through senses, while spontaneous lifestyle, consistent with abnormal people and inconsistent with healthy people shows experience seeking through the mind. Disinhibition is the desire to relieve oneself from social bounds for hedonistic and thrill-seeking ends, through interaction with others. Boredom susceptibility is the aversion to any kind of monotonous task, repetitive experience, or facing boring people [13]. Identifying personalities predisposed to $\mathrm{CAD}$ may be useful to conduct preventive and therapeutic interventions. The aim of the present study was to investigate the association between sensation seeking and $\mathrm{CAD}$.

\section{METHODS}

This study was approved by the scientific committee of Psychology Department at the University of Tabriz. This was a causal-comparative study with a population comprised of all CAD patients referred to Madani Heart Hospital, Tabriz, Iran, and also healthy individuals. Sample groups included 223 patients with $\mathrm{CAD}$ and 255 healthy subjects. Zuckerman Sensation Seeking Scale-Form V (SSS-V) was used, and participants were compared in terms of levels of sensation seeking in four groups. Accordingly, among the patients and healthy participants, 100 patients undergoing treatment for CAD (50 males and 50 females) and 100 healthy people (50 males and 50 females) that matched in terms of age and gender were selected, according to the purposeful sampling method (aged 25 to 64 years). The study tool was Zuckerman's Sensation Seeking Scale form V (SSS-V), which is the brief version of the Zuckerman's Sensation Seeking Scale form IV (SSS-IV), prepared in 1978. Many studies have been conducted on this scale, based on the factor analysis model. This is a 40-item two-option questionnaire with an overall score and four scores for the sub- scales, including thrill and adventure seeking, experience seeking, disinhibition, and boredom susceptibility, and 10 items for each of these subscales. The internal consistency of the $4^{\text {th }}$ and $5^{\text {th }}$ versions of the American and English samples found by Zuckerman et al. (1978) showed that internal consistency of the overall scale in the English sample was about the same as the American samples. The 40 -item scale in version IV showed appropriate internal consistency in the range of $83 \%$ to $86 \%$, with exception of the experience seeking scale [14]. The completion of this questionnaire has no time limit, yet usually does not exceed 10 minutes. Participants are requested to carefully read the instructions and choose one of the answer options. It was also notified that participants should not leave any question unanswered, and should select the option that described their inclination and feelings best. In every item, one of the options scored one and the other zero.

\section{Statistical Analysis}

Data were expressed as mean \pm SD. In the present study, data were analyzed using descriptive statistics as well as Multivariate Analysis of Variance (MANOVA). Prior to analysis of data, Kolmogorov-Smirnov test was used to ensure normal distribution of data and compliance with conditions for using parametric statistics, and the results confirmed normal distribution $(P>0.05)$. Levene's test was used to verify the assumption of equality of variances of groups, and the results confirmed variance equality of study variables, with no significant difference between them $(\mathrm{P}>0.05)$. Then, Wilks' Lambda test was used to show the difference between groups in composition of variables. Results were considered significant at an error probability level of $\mathrm{P}<0.05$.

\section{RESULTS}

Table 1 presents descriptive details of healthy participants and patients of different genders, according to sensation-seeking subscales.

Table 2 shows comparison of groups in terms of sensation-seeking subscales using univariate analysis of variance.

\begin{tabular}{|lcccc|}
\hline \multicolumn{4}{l}{ Table 1: Mean and Standard Deviation in Sensation Seeking Subscales of Patients with Coronary Artery Disease and Healthy Subjects } \\
Male patient & TAS $^{*}$ & ES $^{*}$ & Dis $^{*}$ & BS $^{*}$ \\
Female patient & $4.78 \pm 2.121$ & $2.85 \pm 1.955$ & $2.66 \pm 2.264$ & $2.74 \pm 1.482$ \\
Healthy men & $3.40 \pm 2.185$ & $2.53 \pm 2.513$ & $3.01 \pm 2.107$ & $2.76 \pm 1.492$ \\
Healthy women & $4.37 \pm 2.348$ & $2.43 \pm 1.885$ & $3.31 \pm 1.348$ & $3.58 \pm 1.762$ \\
Total & $5.14 \pm 1.958$ & $2.41 \pm 1.642$ & $2.80 \pm 1.484$ & $2.54 \pm 1.567$ \\
\hline
\end{tabular}

TAS (Thrill and Adventure Seeking); ES (Experience Seeking); Dis (Disinhibition); BS (Boredom Susceptibility)

${ }^{*}$ Mean \pm SD

\begin{tabular}{|lccccc|}
\hline \multicolumn{4}{|l}{ Table 2: Univariate Analysis of Variance for Group Differences in Sensation Seeking Subscales } & & \\
Dependent Variable & Sum of Squares & Mean Squares & F & p-value & Partial Eta Squares \\
TAS & 84.60 & 28.200 & 6.060 & 0.001 & 0.085 \\
ES & 5.895 & 1.965 & 0.479 & 0.697 & 0.007 \\
Dis & 31.855 & 10.618 & 4.253 & 0.006 & 0.061 \\
BS & 12.295 & 4.098 & 1.206 & 0.309 & 0.018 \\
\hline
\end{tabular}

Df $=3$

TAS (Thrill and Adventure Seeking); ES (Experience Seeking); Dis (Disinhibition); BS (Boredom Susceptibility) 


\begin{tabular}{|c|c|c|c|c|}
\hline Men & Women & Mean difference & Std. Error & Sig \\
\hline \multicolumn{5}{|l|}{ TAS } \\
\hline Patient & Patient & 1.380 & 0.431 & 0.003 \\
\hline Healthy & Healthy & -0.780 & 0.431 & 0.072 \\
\hline \multicolumn{5}{|l|}{ ES } \\
\hline Patient & Patient & 0.308 & 0.406 & 0.470 \\
\hline Healthy & Healthy & -2.788 & 0.406 & 1.000 \\
\hline \multicolumn{5}{|l|}{ Dis } \\
\hline Patient & Patient & -0.340 & 0.359 & 0.358 \\
\hline Healthy & Healthy & 0.520 & 0.359 & 0.160 \\
\hline \multicolumn{5}{|l|}{ BS } \\
\hline Patient & Patient & 0.020 & 0.316 & 0.950 \\
\hline Healthy & Healthy & 1.040 & 0.316 & 0.001 \\
\hline
\end{tabular}

TAS (Thrill and Adventure Seeking); ES (Experience Seeking); Dis (Disinhibition); BS (Boredom Susceptibility)

\begin{tabular}{|c|c|c|c|c|}
\hline Patient & Healthy & Mean difference & Std. Error & Sig \\
\hline \multicolumn{5}{|l|}{ TAS } \\
\hline men & men & 0.420 & 0.431 & 0.332 \\
\hline women & women & -1.750 & 0.431 & 0.001 \\
\hline \multicolumn{5}{|l|}{ ES } \\
\hline men & men & 0.420 & 0.406 & 0.301 \\
\hline women & women & 0.122 & 0.406 & 0.767 \\
\hline \multicolumn{5}{|l|}{ Dis } \\
\hline men & men & -0.660 & 0.359 & 0.75 \\
\hline women & women & 0.200 & 0.359 & 0.588 \\
\hline \multicolumn{5}{|l|}{ BS } \\
\hline men & men & -0.840 & 0.316 & 0.009 \\
\hline women & women & 0.220 & 0.316 & 0.487 \\
\hline
\end{tabular}

TAS (Thrill and Adventure Seeking); ES (Experience Seeking); Dis (Disinhibition); BS (Boredom Susceptibility)

There was a significant difference between groups' scores in subscales of experience seeking and boredom susceptibility. However, the difference between groups was insignificant in subscales of thrill and adventure seeking and disinhibition. Paired comparison of groups according to gender is shown in Table 3.

In thrill and adventure seeking subscale, the difference was significant and male patients scored higher than female patients. Moreover, in boredom susceptibility subscale, there was a significant difference between healthy males and healthy females, and healthy males scored higher than healthy females. Table 4 presents comparison of groups, indicating that in thrill and adventure seeking subscale, healthy females scored higher than female patients, and in boredom susceptibility subscale, healthy males scored higher than male patients.

\section{DISCUSSION}

This study aimed at investigating the relationship of sensation seeking levels and gender in $\mathrm{CAD}$ patients and healthy peo- ple. The present study results showed a significant difference in thrill and adventure seeking subscales between patients' groups, according to gender, meaning that male patients scored higher compared to female patients. Furthermore, in the subscale of boredom susceptibility, healthy males scored higher than healthy females. This is in line with the results of a study by Khanjani et al., who showed that males scored higher than females in subscale of boredom susceptibility [15]. Rosenblitt et al. showed that males scored higher than females in subscales of thrill and adventure seeking, experience seeking, and boredom susceptibility [16]. Similar results were also obtained in studies by Namdar et al. [13], Sutker et al., Scourfield et al., Carton et al., Zuckerman, and Zuckerman et al. [17-21]. Such a fundamental difference could be attributed to biological differences between males and females, as well as cultural inclinations and values of society leading females towards stability and uniformity. It is possible that mankind has learnt over many years that as mothers and child-minders, females should always avoid high risk behaviors and emotions to be able to nurture the future generation, as an adventurous and sensation seeking mother is unable to 
remain in one place with specific people and carry on with a monotonous living, and this endangers rearing of children. As a result, societies force females toward lower levels of sensation-seeking [15]. From the perspectives of the learning approach, social reinforcements could be invoked to explain this finding. In many societies, particularly traditional and religious ones, like that in Iran, females are not expected to do dangerous tasks. Since childhood, girls are taught to obey more and venture less, even though, nowadays, because of individualistic and hedonistic culture imported from the West, tendencies toward adventurous behaviors have increased among females in the Iranian society [15].

Results also showed that in comparison to health status, there was a significant difference in the subscale of thrill and adventure seeking, and healthy females had higher tendencies toward thrill and adventure seeking than female patients. In other words, females with $\mathrm{CAD}$ were less adventurous and sensation seekers than healthy females. In addition, there was a significant difference in the subscale of boredom susceptibility, meaning that healthy males scored higher than male patients. This is in line with the results of a study by Namdar et al., who showed that healthy females scored higher than female patients in subscales of thrill and adventure seeking [13]. In another study on the relationship between personality traits and cardiovascular responses to music, extravert male subjects showed a greater reduction in heart rate and blood pressure than introvert male subjects [22]. Considering that there is a relationship between sensation seeking and extraversion, and that sensation seeking could be seen as a subset of extraversion [23], the findings of the present study could be considered consistent with the findings of the above mentioned study. In his studies, Zuckerman proposed the hypothesis of hormonal effects on human sensation-seeking. Other studies showed a negative correlation between blood level of cortisol and sensation-seeking. On the other hand, sensation seekers experience less stress compared to low sensation seekers. Therefore, the reduction of cortisol is an appropriate biological explanation for sensation seeking status [24]. Stress can lead to heart disease through physiological changes. In response to stress, or exposure to a threatening or dangerous situation, heart rate increases, blood pressure rises, and many other changes occur in the body. Furthermore, stress leads to increased blood coagulation, which can cause partial or complete blockage of a coronary arteries, and ultimately heart attack [25].

This research showed that in females, there is a relationship between low scores of thrill and adventure seeking subscale of sensation seeking and CAD; and in males, there is a relationship between low scores of boredom and susceptibility subscale of sensation seeking and CAD.

Therefore, with the identification of individuals with sensation seeking features, it is possible to identify susceptible coronary patients for preventive procedures.

\section{AUTHORS' CONTRIBUTION}

Data collection: Sadeghi, Hakimi; Data analysis and interpretation: Hashemi, Babapour, Ezzati; Drafting the article: Ezzati, Namdar; Critical revision of the article: Namdar, Taban sadeghi, Samani; Final approval of the version to be published: Ezzati, Namdar.

\section{CONFLICTS OF INTERESTS}

There is no conflict of interest.

\section{FUNDING}

The authors declared that there is no funding or support.

\section{REFERENCES}

1. Curtis BM, O'Keefe JH, Jr. Understanding the Mediterranean diet. Could this be the new "gold standard" for heart disease prevention? Postgrad Med. 2002;112(2):35-8, 41-5. PMID: 12198752

2. Namavar A, Haque A. Type D personality and coronary artery disease: Exploring their relationship in younger population of United Arab Emirates. Ibnosina J Med Biomed Sci 2014;6(6):298. DOI: 10.4103/1947-489x.210394

3. Denollet J. Personality, emotional distress and coronary heart disease. Eur J Pers. 1997;11(5):343-57. DOI: 10.1002/(sici)10990984(199712) 11:5<343: : aid-per305>3.0.co;2-p

4. Krantz DS, McCeney MK. Effects of psychological and social factors on organic disease: a critical assessment of research on coronary heart disease. Annu Rev Psychol. 2002;53:341-69. DOI: 10.1146/ annurev.psych.53.100901.135208 PMID: 11752489

5. Denollet J, Vaes J, Brutsaert DL. Inadequate response to treatment in coronary heart disease : adverse effects of type $\mathrm{D}$ personality and younger age on 5-year prognosis and quality of life. Circulation. 2000;102(6):630-5. PMID: 10931802

6. Steptoe A. Psychosocial factors in the aetiology of coronary heart disease. Heart. 1999;82(3):258-9. PMID: 10455068

7. Gellman M, Spitzer S, Ironson G, Llabre M, Saab P, DeCarlo Pasin R, et al. Posture, place, and mood effects on ambulatory blood pressure. Psychophysiology. 1990;27(5):544-51. PMID: 2274617

8. Kamarck TW, Shiffman SM, Smithline L, Goodie JL, Paty JA, Gnys $\mathrm{M}$, et al. Effects of task strain, social conflict, and emotional activation on ambulatory cardiovascular activity: daily life consequences of recurring stress in a multiethnic adult sample. Health Psychol. 1998;17(1):17-29. PMID: 9459066

9. Porter LS, Stone AA, Schwartz JE. Anger expression and ambulatory blood pressure: a comparison of state and trait measures. Psychosom Med. 1999;61(4):454-63. PMID: 10443753

10. Raikkonen K, Matthews KA, Flory JD, Owens JF, Gump BB. Effects of optimism, pessimism, and trait anxiety on ambulatory blood pressure and mood during everyday life. J Pers Soc Psychol. 1999;76(1):104-13. PMID: 9972556

11. Jonassaint CR, Why YP, Bishop GD, Tong EM, Diong SM, Enkelmann $\mathrm{HC}$, et al. The effects of neuroticism and extraversion on cardiovascular reactivity during a mental and an emotional stress task. Int J Psychophysiol. 2009;74(3):274-9. DOI: 10.1016/j.ijpsycho.2009.09.012 PMID: 19818369

12. Zuckerman M. The psychophysiology of sensation seeking. J Pers. 1990;58(1):313-45. PMID: 2198341

13. Namdar H, Sate H, Sadeghi M, Vahedi S, Ezzati D. Emotional Seeking in Patients with Essential Hypertension and Normal Individuals. Med J Tabriz Univ Med Sci Health Serv. 2015;37(2):42-7.

14. Corulla WJ. A further psychometric investigation of the sensation seeking scale form-v and its relationship to the EPQ-R and the I.7 impulsiveness questionnaire. Pers Individ Differ. 1988;9(2):277-87. DOI: $\quad 10.1016 / 0191-8869(88) 90089-\mathrm{x}$

15. Khanjani Z, Fakhraei N, Badri R. A gender-based study of sensation seeking in addicted and normal subjects. J Res Behav Sci. 2011;4:287-95.

16. Rosenblitt JC, Soler H, Johnson SE, Quadagno DM. Sensation seeking and hormones in men and women: exploring the link. Horm Behav. 2001;40(3):396-402. DOI: 10.1006/hbeh.2001.1704 PMID: 11673912

17. Sutker PB, Archer RP, Allain AN. Drug abuse patterns, personality characteristics, and relationships with sex, race, and sensation seeking. J Consult Clin Psychol. 1978;46(6):1374-8. PMID: 730886

18. Scourfield J, Stevens DE, Merikangas KR. Substance abuse, comorbidity, and sensation seeking: gender differences. Compr Psychiatry. 1996;37(6):384-92. PMID: 8932962

19. Carton S, Jouvent R, Widlocher D. Sensation seeking, nicotine de- 
pendence, and smoking motivation in female and male smokers. Addict Behav. 1994;19(3):219-27. PMID: 7942242

20. Zuckerman $\mathrm{M}$. The psychobiological model for impulsive unsocialized sensation seeking: a comparative approach. Neuropsychobiology. 1996;34(3):125-9. PMID: 8916069

21. Zuckerman M, Eysenck S, Eysenck HJ. Sensation seeking in England and America: cross-cultural, age, and sex comparisons. J Consult Clin Psychol. 1978;46(1):139-49. PMID: 627648

22. Namdar H, Taban Sadeghi M, Sabourimoghaddam H, Sadeghi B, Ezzati D. Effects of music on cardiovascular responses in men with essential hypertension compared with healthy men based on introversion and extraversion. J Cardiovasc Thorac Res. 2014;6(3):185-9.
DOI: 10.15171/jcvtr.2014.009 PMID: 25320667

23. Eysenck HJ. Can personality study ever be scientific? J Soc Behav Pers. 1986;1(1):3.

24. Sabouri Moghaddam H, Babapour Kheyroddin J, Ezzati D, Aslan Abadi N, Foroughi Asl R, Sadeghi B, et al. Effects of stressful stimulus on blood pressure and heart rate in patients with cardiovascular disease in comparison with healthy subjects based on emotion seeking levels. J Mod Psychol Res. 2015;10(38):149-65.

25. Khoosfi H, Monirpoor N, Birashk B, Peighambari M. A comparative study of personality factors, stressful life events and social support in coronary heart patients and non- patients. Contemporary psychology. Biann J Iranian Psychol Assoc. 2007;2(3):41-8. 